\title{
Enhancing the gas adsorption capacities of UiO-66 by nanographite addition
}

Alfonso Policicchio $^{1}$, Marc Florent ${ }^{1}$, Alain Celzard ${ }^{2}$, Vanessa Fierro ${ }^{2}$, Jacek Jagiello ${ }^{3}$ and Teresa

J. Bandosz $z^{1}$

${ }^{1}$ Department of Chemistry and Biochemistry, The City College of New York, New York, NY 10031, USA

${ }^{2}$ Université de Lorraine, CNRS, IJL, F-88000 Epinal, France

${ }^{3}$ Micromeritics Instrument Corporation, Norcross, GA 30093, USA

\begin{abstract}
New composites have been synthesized containing nanographite (nGr) particles as platforms for the deposition of UiO-66 crystals. The samples were analyzed by X-ray diffraction, thermogravimetry, $\mathrm{N}_{2}$ adsorption and scanning electron microscopy. The addition of $\mathrm{nGr}$ markedly increased the porosity determined by $\mathrm{N}_{2}$ adsorption $(0.5 \mathrm{~nm}$ ultramicropores were formed, and the volume in pores $>1.1 \mathrm{~nm}$ increased). This was the result of defects formation either on $\mathrm{UiO}-66$ or at the $\mathrm{nGr} / \mathrm{UiO}-66$ interface. To assess the adsorptive properties and the accessibility of the pores, adsorption of $\mathrm{H}_{2}, \mathrm{CO}_{2}, \mathrm{C}_{2} \mathrm{H}_{4}$ and $\mathrm{C}_{2} \mathrm{H}_{6}$ was measured. The results have shown that not only the extent of the porosity but also the interactions with the graphite phase and the accessibility to the pores affect the amount adsorbed and the strength of adsorption. Generally, the formation of composites had a positive effect on the adsorption properties owing to an increased surface heterogeneity and porosity.
\end{abstract}

Keywords: metal organic framework; nanographite; small gas molecule adsorption; defects; porosity; isosteric heat of adsorption 


\section{Introduction}

Metal-organic frameworks (MOFs) are a group of materials represented by a variety of structures and chemistries affecting their properties and applications [1, 2]. Even though they are perfect crystals, this perfection is not always beneficial for the target performance, especially in catalysis. Therefore, in recent years, research has been carried out with focus on increasing the defects populations in otherwise perfect MOFs [3]. The defects in MOFs can arise from crystal imperfections caused mainly by partial ligand replacement [4, 5], missing clusters [6], heterogeneity of ligands [7, 8] or a use of modulators during the MOF synthesis $[9,10]$.

UiO-66 is a well-studied MOF, which exhibits a high surface area, chemical, mechanical and thermal stability [11-13]. The synthesis of this MOF is relatively easy and enables the tunability of its structural defects [4-10]. These defects, besides being known to increase pore volumes and surface areas, also change pores' morphology/distribution and affect the adsorption of gases such as $\mathrm{CO}_{2}$ [14-18], $\mathrm{H}_{2} \mathrm{O}[19,20], \mathrm{H}_{2}[15,21-23], \mathrm{C}_{2} \mathrm{H}_{6}$ [24-27] or $\mathrm{C}_{2} \mathrm{H}_{4}$ [25].

Adsorption of $\mathrm{CO}_{2}$ on UiO-66 has been extensively studied in search of sufficient sequestration media. Both experimental [15-17] and theoretical approaches have been explored [14, 17]. At 0.1 $\mathrm{MPa}$ and $0^{\circ} \mathrm{C}$, adsorbed amounts of $\sim 2 \mathrm{mmol} / \mathrm{g}$ have been reported $[15,16]$. While the heat of adsorption measured by adsorption methods was between 22 and $28 \mathrm{~kJ} / \mathrm{mol}[15$, 16] and increased with the introduction of defects [16], results of infrared spectroscopy at variable temperature suggested that the heat of $\mathrm{CO}_{2}$ adsorption by hydrogen bonding reaches $38 \mathrm{~kJ} / \mathrm{mol}$, and $30.2 \mathrm{~kJ} / \mathrm{mol}$ - by dispersive interactions [14]. Recently, we have reported that defects in UiO66, synthesized in the presence of nanocellulose crystals of various chemistries, not only increased the amount of $\mathrm{CO}_{2}$ adsorbed by about $30 \%$ at $0^{\circ} \mathrm{C}$, compared to UiO-66 (3.25 mol/g 
as compared to $2.5 \mathrm{mmol} / \mathrm{g}$ ), but also led to an increase in the heat of adsorption from 20 to 27 $\mathrm{kJ} / \mathrm{mol}$ [28].

In the case of $\mathrm{H}_{2}$ adsorption on UiO-66, the amount adsorbed at $-196^{\circ} \mathrm{C}$ and $0.1 \mathrm{MPa}$ increased from $1.25 \%$ to $1.50 \%$ upon changing the solvent from ethanol to DMF used in its synthesis [21]. This also resulted in an increase in the homogeneity of the crystals (well defined sizes of 150-200 $\mathrm{nm}$ in DMF) and in an increase in the surface area from $784 \mathrm{~m}^{2} / \mathrm{g}$ in ethanol to 1358 $\mathrm{m}^{2} / \mathrm{g}$ in DMF. In this case, the lower surface area of the sample synthesized in ethanol was linked to impurities due to polymerization products of benzenedicarboxylate (BDC). Nanosized UiO-66 of an enhanced porosity due to the more effective removal of solvent and unreacted BDC from the pores had a surface area of $1434 \mathrm{~m}^{2} / \mathrm{g}$ and a $\mathrm{H}_{2}$ uptake of $1.50 \%$ [15]. Ren et al. studied adsorption of hydrogen in UiO-66 synthesized with various amounts of formic acid as a modulator [23]. They found that the increase in the amount of modulator increased the size of the crystals and the surface area to $1367 \mathrm{~m}^{2} / \mathrm{g}$. On this material, $1.5 \%$ of $\mathrm{H}_{2}$ was adsorbed at $196^{\circ} \mathrm{C}$ and $0.1 \mathrm{MPa}$.

Although the separation of alkanes from alkenes is an industrially important process, UiO-66 has rather rarely been used in this application, likely owing to the lack of unsaturated metal sites, which would provide the specific interactions/ $\pi$-complexation, as in the case of $\mathrm{Cu}-\mathrm{BTC}$ (benzenetricarboxylate) [24]. Nevertheless, Qian at al. [24] reported that the number of carboxyl groups in the linkers of UiO-66 affected the $\mathrm{C}_{2} \mathrm{H}_{6} / \mathrm{C}_{2} \mathrm{H}_{4}$ separation. When 1, 2, 4 BTC (in UiO66- $\mathrm{COOH}$ ) was used as a linker, there was no difference between the amount adsorbed of both species at $25^{\circ} \mathrm{C}$, and about $1.3 \mathrm{mmol} / \mathrm{g}$ were reported. Increasing the number of carboxylic acid in the linker $\left(1,2,4,5-\mathrm{BTEC}\right.$; in $\left.\mathrm{UiO}-66-(\mathrm{COOH})_{2}\right)$ increased the amount adsorbed to 1.8 $\mathrm{mmol} / \mathrm{g}$ and the surface was slightly more favorable for adsorption of $\mathrm{C}_{2} \mathrm{H}_{6}$ compared to that of 
$\mathrm{C}_{2} \mathrm{H}_{4}\left(\sim 0.1 \mathrm{mmol} / \mathrm{g}\right.$ more of $\mathrm{C}_{2} \mathrm{H}_{6}$ was adsorbed at $\left.0.1 \mathrm{MPa}\right)$. The latter happened despite the smaller surface area of UiO-66-(COOH $)_{2}\left(622 \mathrm{~m}^{2} / \mathrm{g}\right.$ compared to $713 \mathrm{~m}^{2} / \mathrm{g}$ for UiO-66-COOH). This trend was linked to smaller pore sizes in UiO-66-(COOH $)_{2}$ compared to those in UiO-66$\mathrm{COOH}$. The heats of $\mathrm{C}_{2} \mathrm{H}_{4}$ adsorption $\left(\mathrm{Q}_{\mathrm{st}}{ }^{\mathrm{o}}\right)$ showed the homogeneity of the surface sites (flat) and $\mathrm{Q}_{\mathrm{st}}{ }^{\mathrm{o}}$ increased from $24.7 \mathrm{~kJ} / \mathrm{mol}$ for UiO-66-COOH to $27.4 \mathrm{~kJ} / \mathrm{mol}$ for UiO-66-(COOH$)_{2}$ [24]. The effect of UiO-66 topology on the adsorption of ethane and ethylene was also studied by $\mathrm{Li}$ and coworkers [25]. On their UiO-66 with a surface area of $1014 \mathrm{~m}^{2} / \mathrm{g}, 67 \%$ more of $\mathrm{C}_{2} \mathrm{H}_{6}$ than that of $\mathrm{C}_{2} \mathrm{H}_{4}$ was adsorbed, and the heats of adsorption were 26 and $24 \mathrm{~kJ} / \mathrm{mol}$, respectively. The difference in the heat of adsorption was linked do the difference in the polarity of these two molecules. The adsorption of ethane at $30^{\circ} \mathrm{C}$ on UiO- 66 was studied by Llewellyn and coworkers [26], who measured a capacity of $1.7 \mathrm{mmol} / \mathrm{g}$ and a heat of adsorption of $\sim 32 \mathrm{~kJ} / \mathrm{mol}$ on a material having a surface area of $\sim 1050 \mathrm{~m}^{2} / \mathrm{g}$.

Considering that a small alteration in the porosity of UiO-66 and defects in their structure were reported to affect the gas adsorption behavior, the objective of this paper is to investigate the effects of the addition of nanographite ( 1 to 6 wt. \%) with particle sizes of about $19 \mu \mathrm{m}$ on the porous properties and the gas adsorption behavior of the final UiO-66/nanographite composites. Since the nanographite particles are much larger than crystals/aggregates of UiO-66 [23], they are expected to work as platforms for the deposition of the latter. Owing to the lack of functional groups on the basal planes of nanographite flakes [29], the UiO-66 deposition might occur mainly via dispersive forces and due to the affinity of the organic linker (BTC) for the graphite surface. This is expected to create either an interface or defects in the MOF phase and, as a consequence, to increase the porosity. Although composites containing UiO-66 and graphite oxide have been synthesized and used as $\mathrm{CO}_{2}$ adsorbents, resulting in an increased storage 
capacity $[17,18]$, their mechanism of formation was different than that expected here due to the lack of oxygen groups on nanographite used in our approach. These defects can be either of chemical or physical in nature and their geometric dimensions should be rather small and of the order of the fraction of a nanometer. Therefore, to test the extent of the approach applied, the surface accessibility of the synthesized materials has been investigated with regard to adsorption of $\mathrm{N}_{2}, \mathrm{CO}_{2}, \mathrm{H}_{2}, \mathrm{C}_{2} \mathrm{H}_{6}$ and $\mathrm{C}_{2} \mathrm{H}_{4}$. Even though nitrogen is commonly used to evaluate the porosity [30], despite its known kinetic limitations to access very small pores, we have also measured the adsorption of hydrogen at $-196^{\circ} \mathrm{C} . \mathrm{CO}_{2}$ was not used for the textural characterization owing to is possible specific interaction with the surface of adsorbents [31].The isosteric heats of adsorption were calculated for $\mathrm{CO}_{2}, \mathrm{C}_{2} \mathrm{H}_{6}$ and $\mathrm{C}_{2} \mathrm{H}_{4}$ from their adsorption isotherms measured at least at two temperatures. The heats of adsorption of $\mathrm{C}_{2} \mathrm{H}_{6}$ and $\mathrm{C}_{2} \mathrm{H}_{4}$ were analyzed in details since the larger sizes of these molecules than other chosen by us as the porosity probes might affect the surface interactions. Moreover $\pi$ bond of $\mathrm{C}_{2} \mathrm{H}_{4}$ might affect the strength of adsorption if acidic groups are on the accessible surface [32]. The adsorption of several small molecules on UiO-66/nanographite composites with different contents of $\mathrm{nGr}$ allowed understanding the effect of nanographite on the final performances of the materials.

\section{Experimental}

\subsection{Materials}

All chemicals, zirconium tetrachloride $\left(\mathrm{ZrCl}_{4}\right), \quad \mathrm{N}, \mathrm{N}$-dimethylformamide (DMF, 99\%), terephthalic acid $\left(\mathrm{C}_{8} \mathrm{H}_{6} \mathrm{O}_{4}, 99+\%\right)$, hydrochloric acid $(\mathrm{HCl}, 37 \%)$ and ethanol $(\mathrm{EtOH}, 96 \%)$ were supplied by either Alfa Aesar, Acros organics or VWR and used as received. Nano-sized graphite (Nano-19) was supplied by Asbury Graphite Mills Ltd., USA. 


\subsection{Synthesis of materials}

All UiO-66 and composite samples were synthesized following the procedure reported elsewhere $[11,12]$, with slight modifications. The experimental steps were as follows: Step 1: A $120 \mathrm{~mL}$ vial was loaded with $4 \mathrm{~mL}$ of concentrated $\mathrm{HCl}, 0.5 \mathrm{~g}$ of $\mathrm{ZrCl}_{4}$ and $20 \mathrm{~mL}$ of DMF. Then, the mixture was sonicated for 20 minutes until complete dissolution; Step 2: $40 \mathrm{~mL}$ of DMF and 0.5 $\mathrm{g}$ of $\mathrm{C}_{8} \mathrm{H}_{6} \mathrm{O}_{4}$ (ligand) were added to the solution, sonicated for 20 minutes and then heated overnight at $80^{\circ} \mathrm{C}$; Step 3: The resulting product was filtered off, washed with DMF $(8 \times 30 \mathrm{~mL})$ and subsequently with $\mathrm{EtOH}(8 \times 30 \mathrm{~mL})$ to remove the excess of unreacted organic linkers. The final product was dried in a vacuum oven at $90^{\circ} \mathrm{C}$ for $24 \mathrm{~h}$ before being analyzed.

The composite materials were synthesized by following exactly the same procedure as described above but 1,2, and $6 \%$ of nanographite (based on the final mass of MOF) were added in the first step. The samples were labeled as UiO-66 and UiO-66-nGr1, UiO-66-nGr2 and UiO-66-nGr6 for the composites with increasing nanographite contents.

\subsection{Analysis Methods}

\section{Textural and morphological characterization}

Nitrogen adsorption isotherms were measured at $-196^{\circ} \mathrm{C}$ on a Micromeritics ASAP 2020 instrument. Prior to each measurement, each sample was outgassed overnight at $150^{\circ} \mathrm{C}$ until a constant vacuum of $10^{-7} \mathrm{kPa}$ was reached. The Brunauer-Emmett-Teller (BET) method within a relative pressure range of $0.05-0.15$ was used to calculate the specific area $\left(S_{\mathrm{BET}}\right)$ while the total pore volume $\left(V_{\mathrm{T}}\right)$ was calculated from the $\mathrm{N}_{2}$ uptake at relative pressure $\mathrm{p} / \mathrm{p}_{\mathrm{o}}$ of 0.998 .

The Non-Local Density Functional Theory in its two-dimensional version, 2D-NLDFT, considering slit-shaped pores with energetically heterogeneous and rough walls [33], was used to 
estimate the volume of micropores, $V_{\text {mic }}$, and ultramicropores $\left(V_{<0.7 \mathrm{~nm}}\right)$ and to obtain the pore size distributions (PSDs). The volume of mesopores, $V_{\text {mes, }}$ was calculated as a difference between $V_{\mathrm{T}}$ and $V_{\text {mic. }}$

X-ray diffraction (XRD) patterns were collected with a Philips PANalytical X'Pert X-ray diffractometer using $\mathrm{CuK}_{\alpha}(40 \mathrm{kV}, 40 \mathrm{~mA})$ radiation. All the measurements were acquired in the 2-theta $(2 \theta)$ range from $5^{\circ}$ to $70^{\circ}$, in steps of $0.02^{\circ}$, and with a time of 0.5 s per step.

Scanning electron images were recorded using a Zeiss Supra 55 VP scanning electron microscope (SEM) with an electron beam of $5 \mathrm{keV}$.

Thermal analysis was performed using an SDT Q600 of TA Instruments. All the samples were analyzed under helium and air flow $(100 \mathrm{~mL} / \mathrm{min})$, heating them up to $1000^{\circ} \mathrm{C}$ at $10^{\circ} \mathrm{C} / \mathrm{min}$. The two thermogravimetric (TG) curves were collected, and the corresponding differential thermal gravimetric (DTG) curves were calculated in order to determine the thermal behavior of the samples.

\section{Adsorption measurements}

$\mathrm{CO}_{2}$ adsorption isotherms at three different temperatures $\left(0^{\circ} \mathrm{C}, 20^{\circ} \mathrm{C}\right.$ and $\left.40^{\circ} \mathrm{C}\right)$ were measured using an ASAP 2020 (Micromeritics) up to $120 \mathrm{kPa}$. Each sample was outgassed for $12 \mathrm{~h}$ at $150^{\circ} \mathrm{C}$ under vacuum $\left(\mathrm{P}<10^{-7} \mathrm{kPa}\right)$ prior to each $\mathrm{CO}_{2}$ adsorption test.

$\mathrm{H}_{2}$ adsorption capacity was evaluated at $-196^{\circ} \mathrm{C}$ up to $100 \mathrm{kPa}$ by using a 3Flex automatic device (Micromeritics) equipped with a high-vacuum system and three $0.013 \mathrm{kPa}$ pressure transducers, one per analysis port. The samples were outgassed for $24 \mathrm{~h}$ at $120^{\circ} \mathrm{C}$ under vacuum $\left(\mathrm{P}<10^{-7} \mathrm{kPa}\right.$ ) for at least $24 \mathrm{~h}$ before being weighed. An additional outgassing was carried out for at least 6 hours more on the analysis ports at the same temperature and under the same final vacuum as in the previous outgassing step. High-resolution $\mathrm{H}_{2}$ isotherms were obtained by 
dosing small hydrogen amounts, as low as $3 \mathrm{~cm}^{3} / \mathrm{g}$. The determination of the warm and cold volume was carried out after $\mathrm{H}_{2}$ adsorption-desorption analysis to avoid any possibility of a helium entrapment in the ultramicroporosity.

Measurements of $\mathrm{C}_{2} \mathrm{H}_{4}$ and $\mathrm{C}_{2} \mathrm{H}_{6}$ isotherms at -58 and $-73^{\circ} \mathrm{C}$ were carried out using again the high-resolution Micromeritics 3Flex adsorption instrument. The latter was equipped with a highvacuum system, three 0.1 Torr pressure transducers, and was coupled with a cryostat (Cold Edge Technologies). The isotherms of $\mathrm{C}_{2} \mathrm{H}_{4}$ and $\mathrm{C}_{2} \mathrm{H}_{6}$ as well as $\mathrm{CO}_{2}$ at different temperatures were used to calculate the isosteric heats of adsorption. The calculations were performed using the analytical form of virial equation [34].

\section{Results and Discussion}

The X-ray diffraction patterns of the synthesized samples are presented in Figure 1. Although the diffraction peaks of the composite materials resemble those of UiO-66, two main diffraction peaks at $2 \theta$ less than $10^{\circ}$ show a marked disturbance in the crystal structure, indicating some shortening of the lattice parameters. This might be related to the pores of smaller sizes than those in the parent UiO-66 materials [35]. 

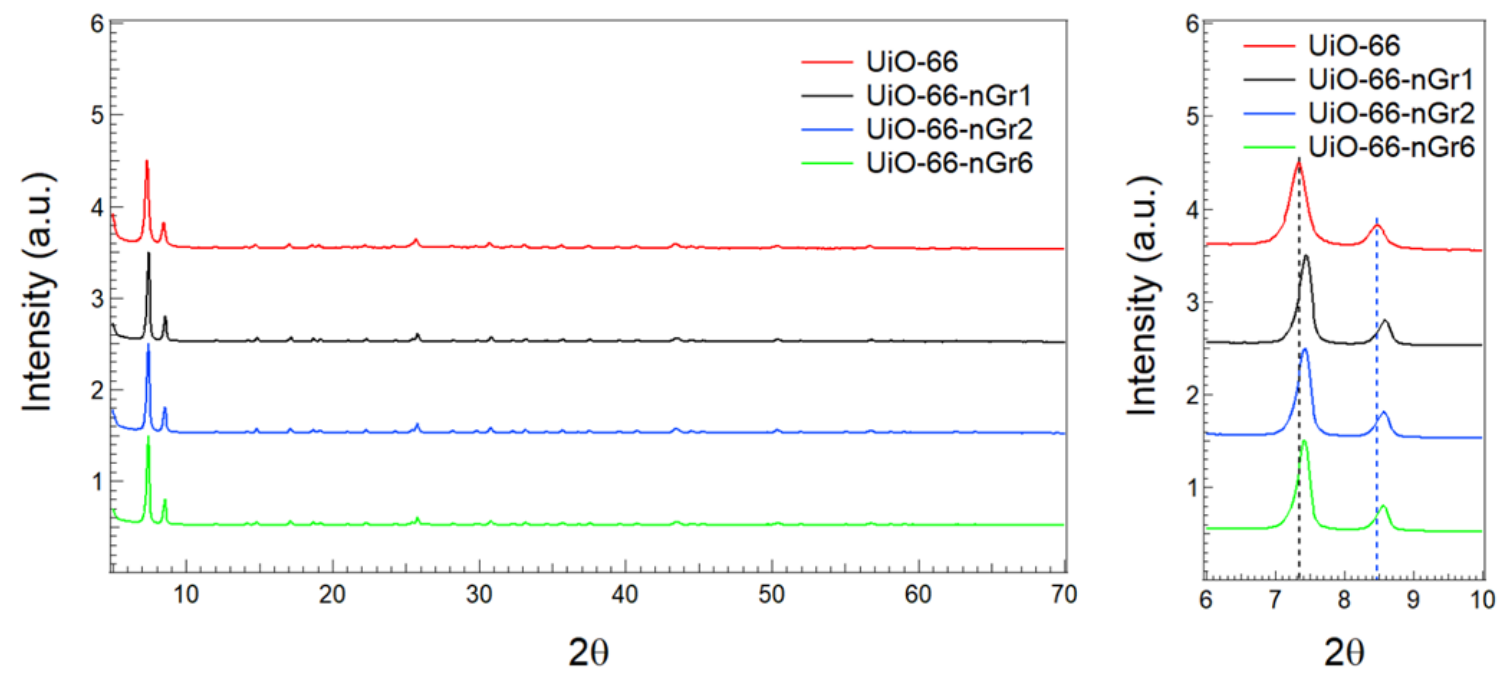

Figure 1. XRD patterns of UiO-66 and its composites with nGr.
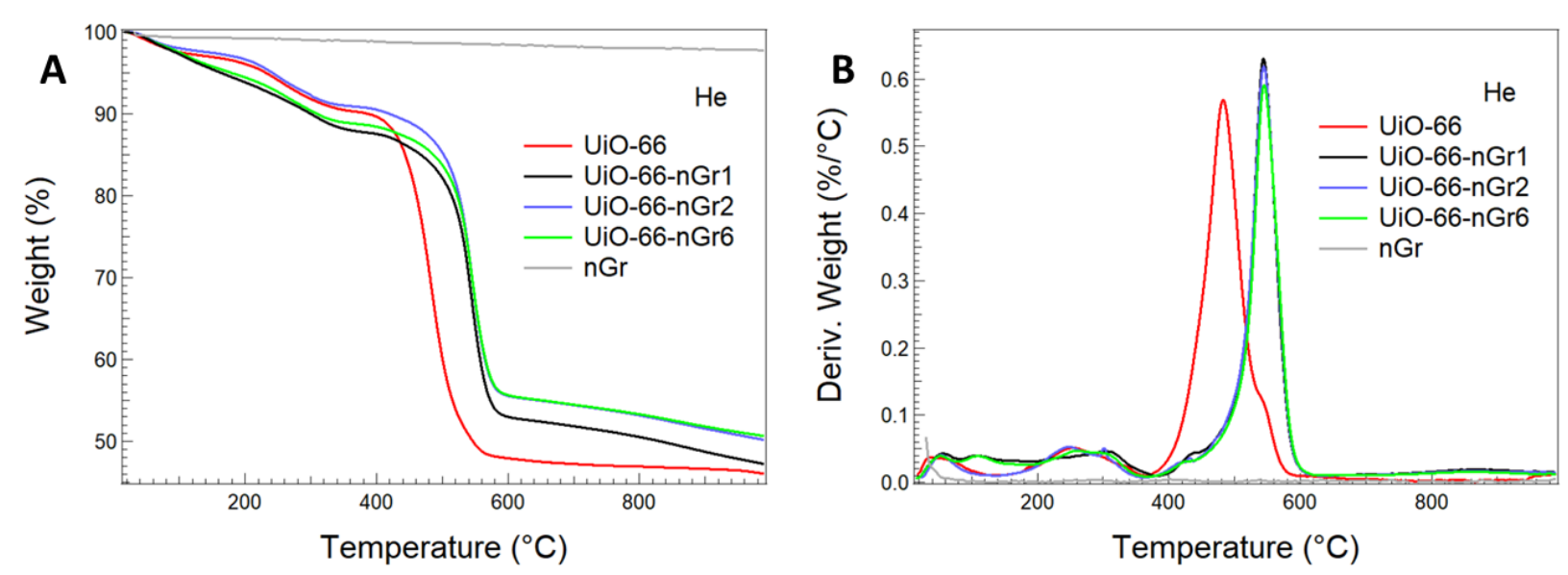

Figure 2. TG (A) and DTG (B) curves under helium flow for pure UiO-66, nGr and UiO-66-nGr composite samples.

TG and DTG curves measured in helium are collected in Figure 2. Based on the thermal stability of the composites upon addition of $\mathrm{nGr}$, they bring indirect information about the change in the chemical composition of our composites. While the linkers in UiO-66 decompose at $460^{\circ} \mathrm{C}$, causing the collapsing of the MOF structure $[11,36]$, this process for all composites takes place 
at a temperature of about $80^{\circ} \mathrm{C}$ higher. This shift might be related to the change in a heat capacity upon the addition of the nanographite phase. This change in the heat capacity might also be due to the expected alteration in the samples' porosity. Interestingly, the decomposition event of the composites overlaps with a small shoulder seen on the UiO-66 DTG curve, which likely suggests the imperfection of our UiO-66 structure. A broad peak between 200 and $400^{\circ} \mathrm{C}$ is linked to the removal of the residual solvent. This process occurs over a broader temperature range for the composites and might be caused by the interaction of the solvent with the nGr phase.

The results of thermal analysis in air are presented in Figures $1 \mathrm{~S}$ and $2 \mathrm{~S}$ of the Supplementary Information. From these data, assuming that the missing linkers are the main defects in our materials, and based on the approach of Katz et al. [12], the number of linkers was calculated. The obtained results indicate that 8, 7.8, 7.8 and 7.6 linkers are present per node in UiO-66, UiO66-nGr, UiO-66-nGr2 and UiO-66-nGr6, respectively. Since the ideal structure is expected to have 12 linkers, all our materials can be considered defective and the level of defects is higher in the composites and increases with an increase in the $\mathrm{nGr}$ content.
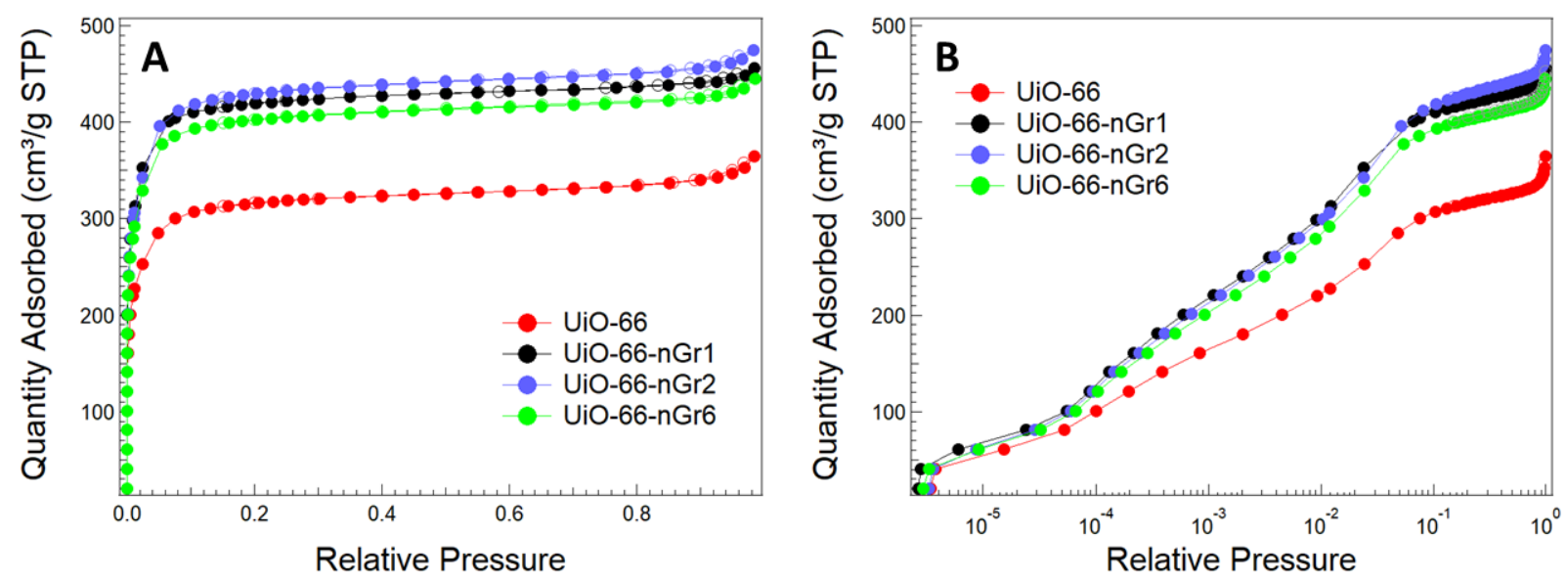

Figure 3. Nitrogen adsorption isotherms in linear (A) and logarithmic (B) scale. 

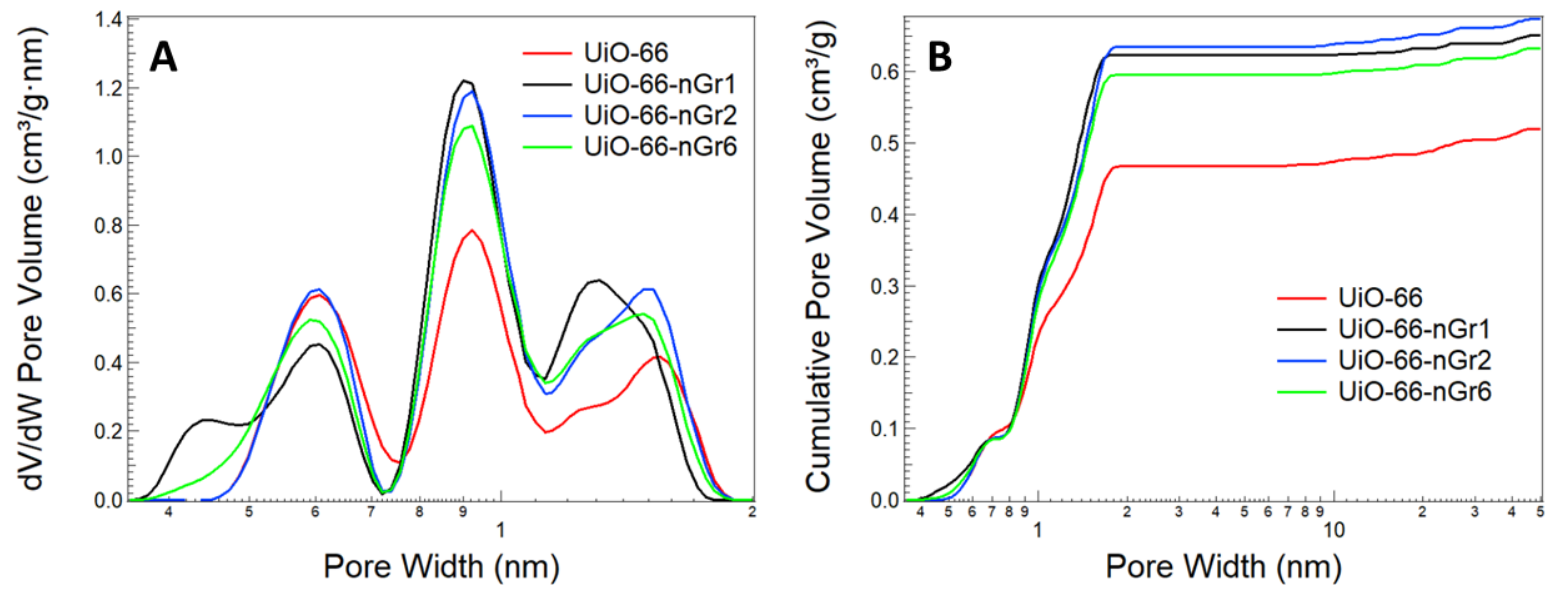

Figure 4. Differential pore size distributions calculated from $\mathrm{N}_{2}$ isotherms using the 2D-NLDFT up to $2 \mathrm{~nm}(\mathrm{~A})$ and cumulative pore volume (B).

This increase in the level of defects should be reflected in an increased porosity. The nitrogen adsorption isotherms and the pore size distributions calculated from them [33] are presented in Figures 3 and 4, respectively. The addition of nGr increased the volume of $\mathrm{N}_{2}$ adsorbed, and the calculated surface areas of the composites increased by about $30 \%$ compared to that of UiO-66 (Table 1). This increase in the surface area is consistent with the decrease in the numbers of linkers per node discussed above. Interestingly, no trend in the porosity development was found with an increase in the nGr content, and the $S_{\mathrm{BET}}$ of all composites remained at the level of about $1600 \mathrm{~m}^{2} / \mathrm{g}$. The volumes of ultra-, micro-, mesopores and the total pore volumes of the composites are also higher than those of UiO-66. 
Table 1. Textural parameters calculated from $\mathrm{N}_{2}$ adsorption isotherms at $-196^{\circ} \mathrm{C}$.

\begin{tabular}{|l|c|c|c|c|c|}
\hline \multicolumn{1}{|c|}{ Sample } & $\begin{array}{c}S_{\mathrm{BET}} \\
{\left[\mathrm{m}^{2} / \mathrm{g}\right]}\end{array}$ & $\begin{array}{c}V_{<1 \mathrm{~nm}} \\
{\left[\mathrm{~cm}^{3} / \mathrm{g}\right]}\end{array}$ & $\begin{array}{c}V_{\text {mic }} \\
{\left[\mathrm{cm}^{3} / \mathrm{g}\right]}\end{array}$ & $\begin{array}{c}V_{\text {mes }} \\
{\left[\mathrm{cm}^{3} / \mathrm{g}\right]}\end{array}$ & $\begin{array}{c}V_{\mathrm{T}} \\
{\left[\mathrm{cm}^{3} / \mathrm{g}\right]}\end{array}$ \\
\hline UiO-66 & 1192 & 0.240 & 0.468 & 0.052 & 0.520 \\
\hline UiO-66-nGr1 & 1598 & 0.314 & 0.623 & 0.028 & 0.651 \\
\hline UiO-66-nGr2 & 1623 & 0.304 & 0.635 & 0.039 & 0.674 \\
\hline UiO-66-nGr6 & 1526 & 0.290 & 0.596 & 0.037 & 0.633 \\
\hline
\end{tabular}

Table 2. $\mathrm{CO}_{2}, \mathrm{C}_{2} \mathrm{H}_{4}, \mathrm{C}_{2} \mathrm{H}_{6}$ and $\mathrm{H}_{2}$ adsorption capacity at $100 \mathrm{kPa}$.

\begin{tabular}{|c|c|c|c|c|c|c|c|c|}
\hline \multirow[t]{2}{*}{ Sample } & \multicolumn{3}{|c|}{$\begin{array}{c}\mathrm{CO}_{2} \\
\text { uptake } \\
{[\mathrm{mmol} / \mathrm{g}]}\end{array}$} & \multicolumn{2}{|c|}{$\begin{array}{c}\mathrm{C}_{2} \mathrm{H}_{4} \\
\text { uptake } \\
{[\mathrm{mmol} / \mathrm{g}]}\end{array}$} & \multicolumn{2}{|c|}{$\begin{array}{c}\mathrm{C}_{2} \mathrm{H}_{6} \\
\text { uptake } \\
{[\mathrm{mmol} / \mathrm{g}]}\end{array}$} & \multirow{2}{*}{$\begin{array}{c}\mathrm{H}_{2} \\
\text { uptake } \\
\text { [wt. \%] }\end{array}$} \\
\hline & $0^{\circ} \mathrm{C}$ & $20^{\circ} \mathrm{C}$ & $40^{\circ} \mathrm{C}$ & $-58^{\circ} \mathrm{C}$ & $-73^{\circ} \mathrm{C}$ & $-58^{\circ} \mathrm{C}$ & $-73^{\circ} \mathrm{C}$ & \\
\hline UiO-66 & 2.51 & 1.73 & 1.14 & 6.77 & 7.84 & 6.80 & 7.47 & 1.27 \\
\hline UiO-66-nGr1 & 2.99 & 2.02 & 1.33 & & & & & 1.41 \\
\hline UiO-66-nGr2 & 2.87 & 1.99 & 1.25 & 9.62 & 11.14 & 9.72 & 10.66 & 1.48 \\
\hline UiO-66-nGr6 & 2.94 & 1.99 & 1.20 & & & & & 1.56 \\
\hline
\end{tabular}

The pore size distributions calculated from the $\mathrm{N}_{2}$ adsorption isotherms (Figure 4) bring more details about the alterations in the porous texture of our materials. As expected from the structure of UiO-66, the predominant pore sizes should be $\sim 0.6 \mathrm{~nm}$ and $\sim 0.9 \mathrm{~nm}$, which represent tetrahedral and octahedral cavities [19]. Defects such as missing linkers and missing clusters are expected to increase the sizes of these latter pores $[6,12,37]$. The striking difference between 
UiO-66 and the composites is the appearance, in the latter materials, of pores smaller than 0.5 $\mathrm{nm}$ and an increase in the volume of pores wider than $1.1 \mathrm{~nm}$ in their size. This effect is especially seen for the composite with the smallest amount of nGr. A detailed comparison of the change in the predominant pore sizes based on the PSDs is presented in Figure 5, where it is clearly seen that the greatest effect is an increase in pores wider than $0.7 \mathrm{~nm}$ upon the composite formation. This increase in the porosity is due to both, the pores of diameter between 0.7 and 1.1 $\mathrm{nm}$, which represent the octahedral cavities, and to pores wider than $1.1 \mathrm{~nm}$, which are assigned to defects such as missing linkers $[12,37]$ and clusters [6]. Pores smaller than $0.5 \mathrm{~nm}$ might represent the interface between $\mathrm{nGr}$ and UiO-crystal deposited on the nGr particles and thus, the smallest amount of nGr added might result in the highest dispersion of this phase and therefore in a more extended interface.

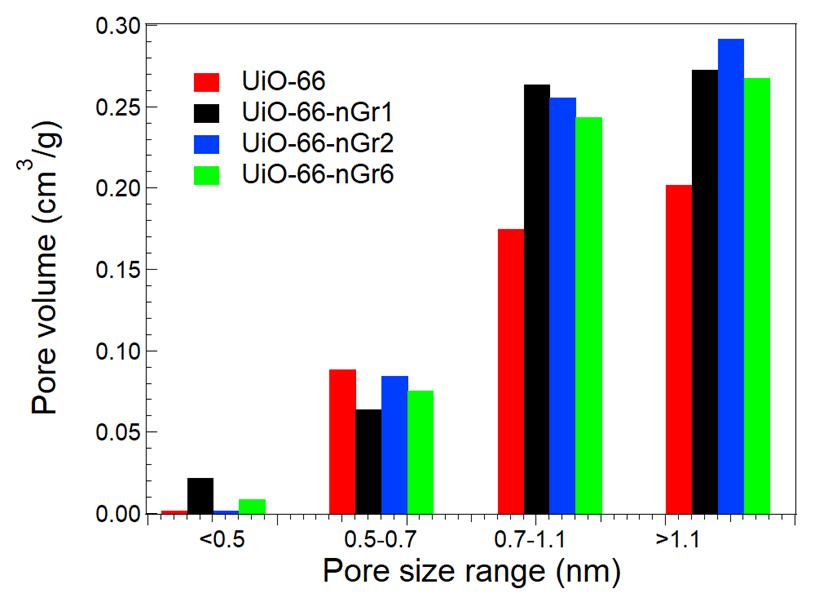

Figure 5. Pore volumes in the different diameter ranges deduced from the pore size distributions given in Figure 4.

Figure 6 shows SEM images of UiO-66 and UiO-66-nGr2, which confirmed that UiO-66 is deposited on nGr flakes and that "wall structures" of UiO-66 are assembled horizontally. This morphology might increase the accessibility of the adsorbates to the UiO-66 adsorption 
sites/pores. The SEM images of $\mathrm{nGr}$ are presented in Figure $3 \mathrm{~S}$ of the Supplementary Information.
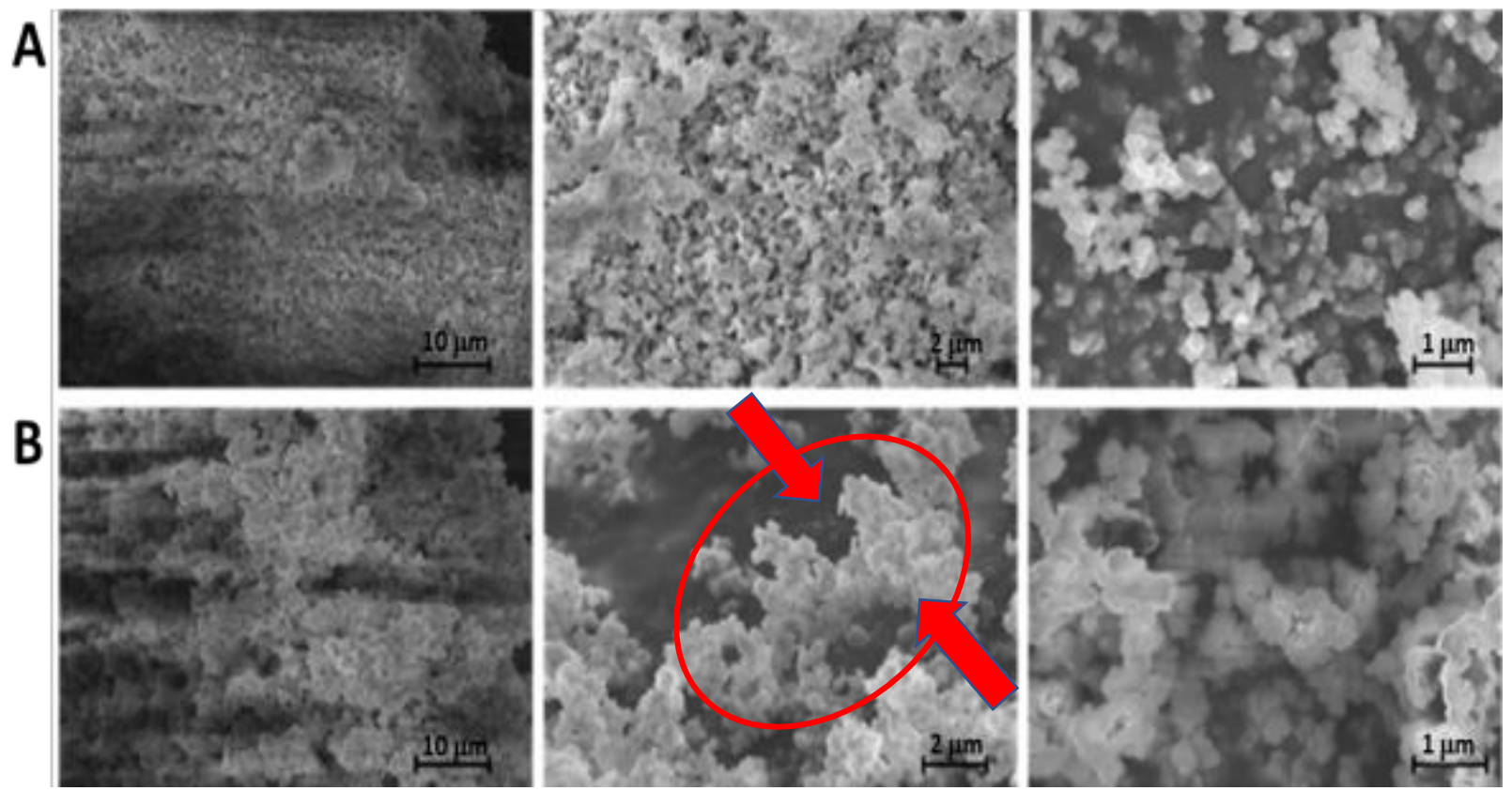

Figure 6. SEM images of pure UiO-66 (A) and UiO-66-nGr2 composite (B) samples. The assembled wall of nanoparticles on the $\mathrm{nGr}$ surface is marked in the bottom middle micrograph.

Figure 7 shows the $\mathrm{CO}_{2}$ adsorption isotherms measured on the four materials at 0,20 and $40^{\circ} \mathrm{C}$. The amounts of $\mathrm{CO}_{2}$ adsorbed at atmospheric pressure are compared in Table 2 and are in the range of those reported in the literature [14-18]. Upon the composite formation, a $20 \%$ increase in the amount of $\mathrm{CO}_{2}$ adsorbed was found. The best performing sample is UiO-66-nGr1, and we link it to its highest volume of pores smaller than $0.5 \mathrm{~nm}$ in which the adsorption forces for $\mathrm{CO}_{2}$ are the strongest and where, at the low relative pressure, the density of $\mathrm{CO}_{2}$ is the highest [38]. The amount of $\mathrm{CO}_{2}$ adsorbed on UiO-66-nGr2 and UiO-66-nGr 6 is similar to that on UiO-66nGr1, which is in agreement with the similarities in the volume of ultramicropores in the 
composite materials. The $\mathrm{CO}_{2}$ uptake decreased with the increasing temperature, from $3 \mathrm{mmol} / \mathrm{g}$ at $0^{\circ} \mathrm{C}$ to $1.2 \mathrm{mmol} / \mathrm{g}$ at $40^{\circ} \mathrm{C}$ for $\mathrm{UiO}-66-\mathrm{nGr} 1$, in good agreement with the exothermic nature of $\mathrm{CO}_{2}$ adsorption on these materials.
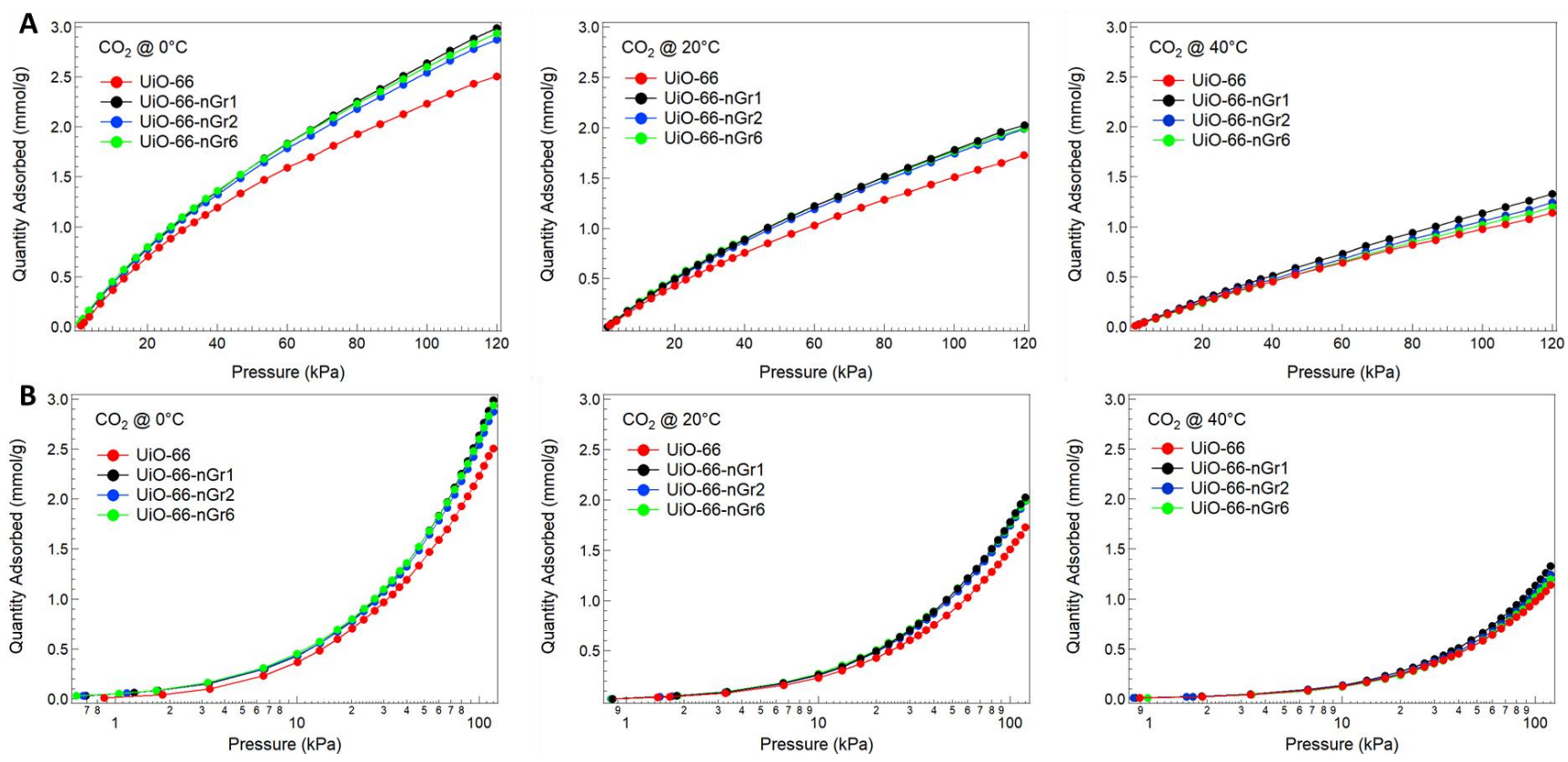

Figure 7. $\mathrm{CO}_{2}$ adsorption isotherms on UiO- 66 composites at $0^{\circ} \mathrm{C}, 20^{\circ} \mathrm{C}$ and $40^{\circ} \mathrm{C}$ in the pressure range $0-120 \mathrm{kPa}$ on $(\mathrm{A})$ linear and $(\mathrm{B})$ logarithmic scale.

Figure 8A shows the isosteric heats of $\mathrm{CO}_{2}$ adsorption, whose values are in the range of those reported in the literature $[15,16]$. Even though there is no visible trend in the amount adsorbed with an increase in the amount of $\mathrm{nGr}$, an increase in the heats of adsorption was observed with an increase in the nGr content (Figure 9A). The latter suggests that the addition of nGr not only enhanced the amount of $\mathrm{CO}_{2}$ adsorbed but also increased the strength of $\mathrm{CO}_{2}$ adsorption, which might be related to a denser array of carbon atoms in nGr. It is important to mention that the heats of adsorption show little variations with the surface coverage, suggesting the homogeneity of the adsorption centers occupied by $\mathrm{CO}_{2}$ in each sample at our experimental conditions. Thus, based on the amount of $\mathrm{CO}_{2}$ adsorbed only $0.050 \mathrm{~cm}^{3} / \mathrm{g}$ would be covered. Therefore, the 
volume occupied by $\mathrm{CO}_{2}$ represents only a small fraction of the total pore volume and, based on the $\mathrm{N}_{2}$ adsorption results, the pores that have very homogeneous sizes contribute to this volume in all the samples.
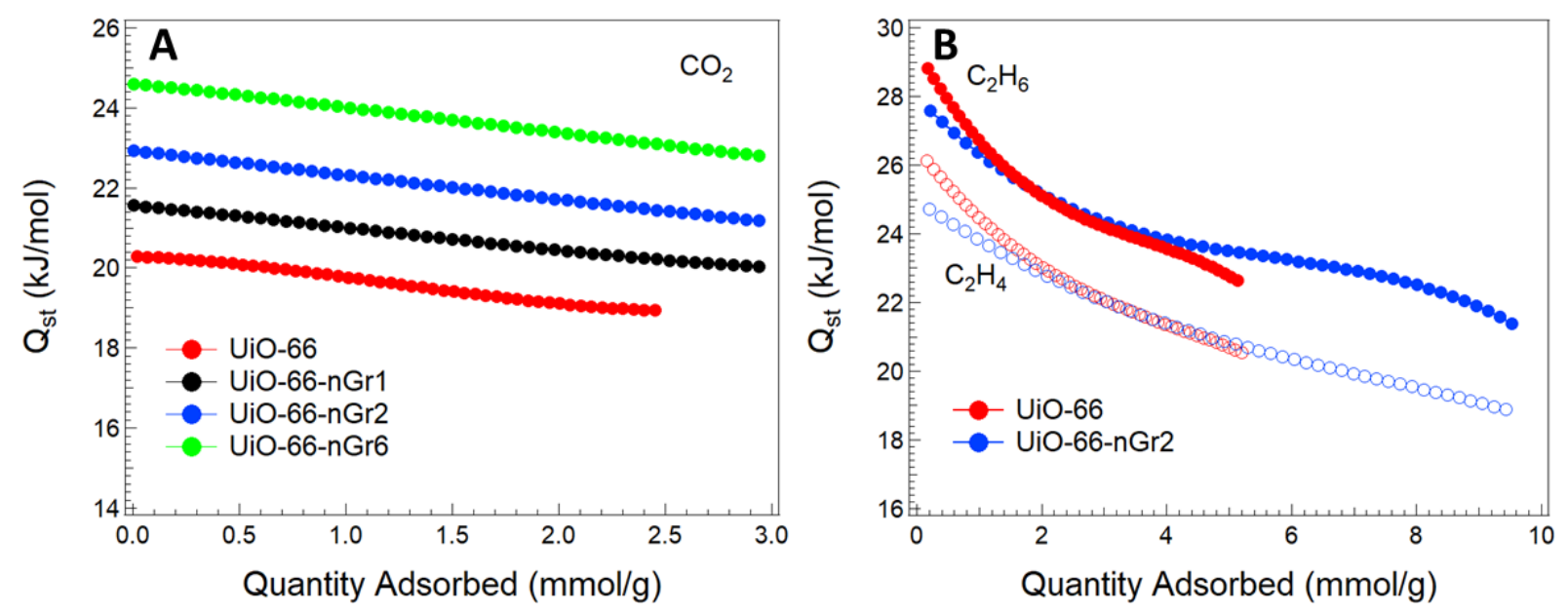

Figure 8. Isosteric heats of adsorption $\left(Q_{\mathrm{st}}\right)$ of $\mathrm{CO}_{2}(\mathrm{~A})$ and $\mathrm{C}_{2} \mathrm{H}_{4}$ (open symbols) $/ \mathrm{C}_{2} \mathrm{H}_{6}$ (solid symbols) (B) on pure UiO-66 (red) and composite samples (blue).
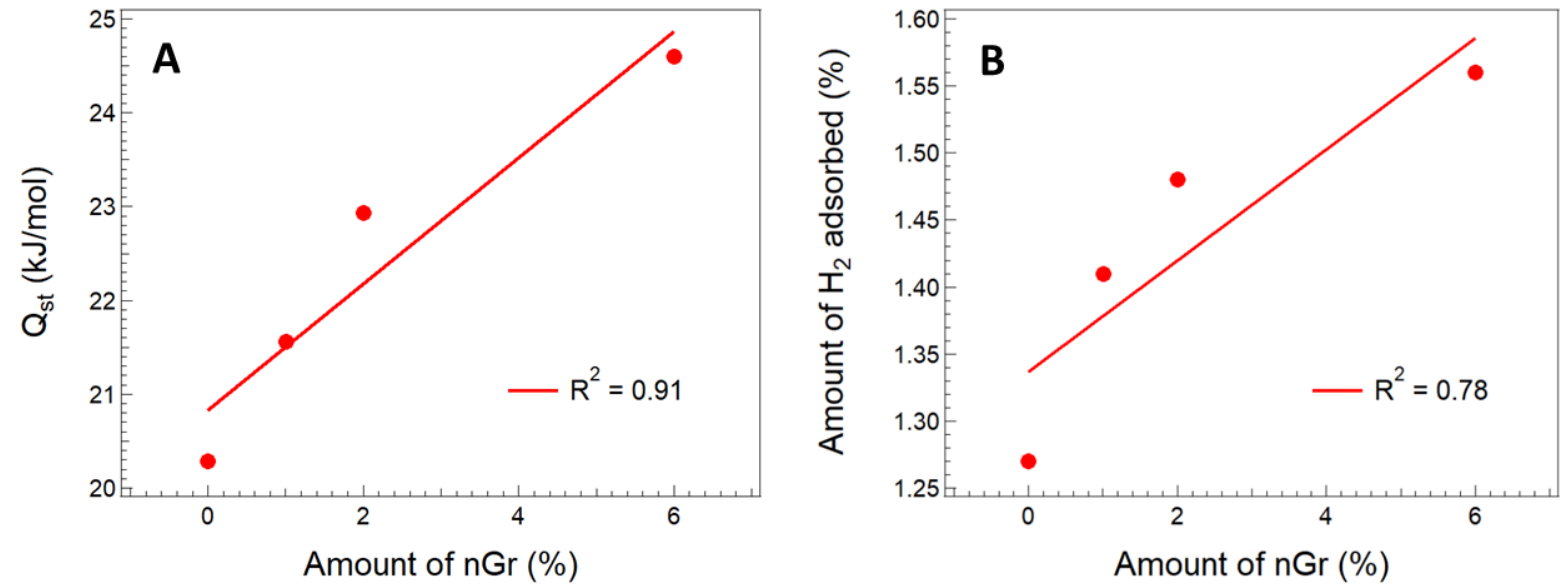

Figure 9. A) Relationship between the isosteric heat of $\mathrm{CO}_{2}$ adsorption at zero coverage and the amount of $\mathrm{nGr}$ in the composites; B) relationship between the amount of $\mathrm{H}_{2}$ adsorbed and the amount of $\mathrm{nGr}$ in the composites. 
Figure 10 shows the $\mathrm{H}_{2}$ adsorption-desorption isotherms measured at $-196^{\circ} \mathrm{C}$ on $\mathrm{UiO}-66$ and its composites. Desorption was fully reversible for all materials studied. Table 2 shows the hydrogen amounts adsorbed at $100 \mathrm{kPa}$, which are similar to those reported in the literature [15, $21,22]$. As in the case of $\mathrm{CO}_{2}$, the amount of hydrogen adsorbed in composites was higher than in pure $\mathrm{UiO}-66$. However, unlike $\mathrm{CO}_{2}$, a clear increase in the hydrogen uptake with the increase in the $\mathrm{nGr}$ content was found observed (Figure 9B). On UiO-66-nGr6, $23 \%$ more of $\mathrm{H}_{2}$ was adsorbed than on UiO-66. Even though $\mathrm{H}_{2}$ is expected to be adsorbed in the smallest pores, no trend between the amount adsorbed and the porosity could be found taking into consideration the pore texture analyzed by $\mathrm{N}_{2}$ adsorption. The molecular diameter of $\mathrm{N}_{2}$ is $0.349 \mathrm{~nm}$ while that of $\mathrm{H}_{2}$ is $0.296 \mathrm{~nm}$, therefore $\mathrm{H}_{2}$ molecules should have access to pore diameters that are not accessible by $\mathrm{N}_{2}$ molecules [39, 40]. Moreover, the absolute quadrupole moment of $\mathrm{N}_{2}$ is higher than that of $\mathrm{H}_{2}, 0.46$ and 0.28 [41], respectively, and this could also have an effect on the differences observed [40]. Thus, the dependence on the amount of nGr added might be related to the specific morphology of the composite and to the enhanced diffusion of $\mathrm{H}_{2}$ at $-196^{\circ} \mathrm{C}$ to the UiO-66 units assembled in the vertical pseudo-walls. 

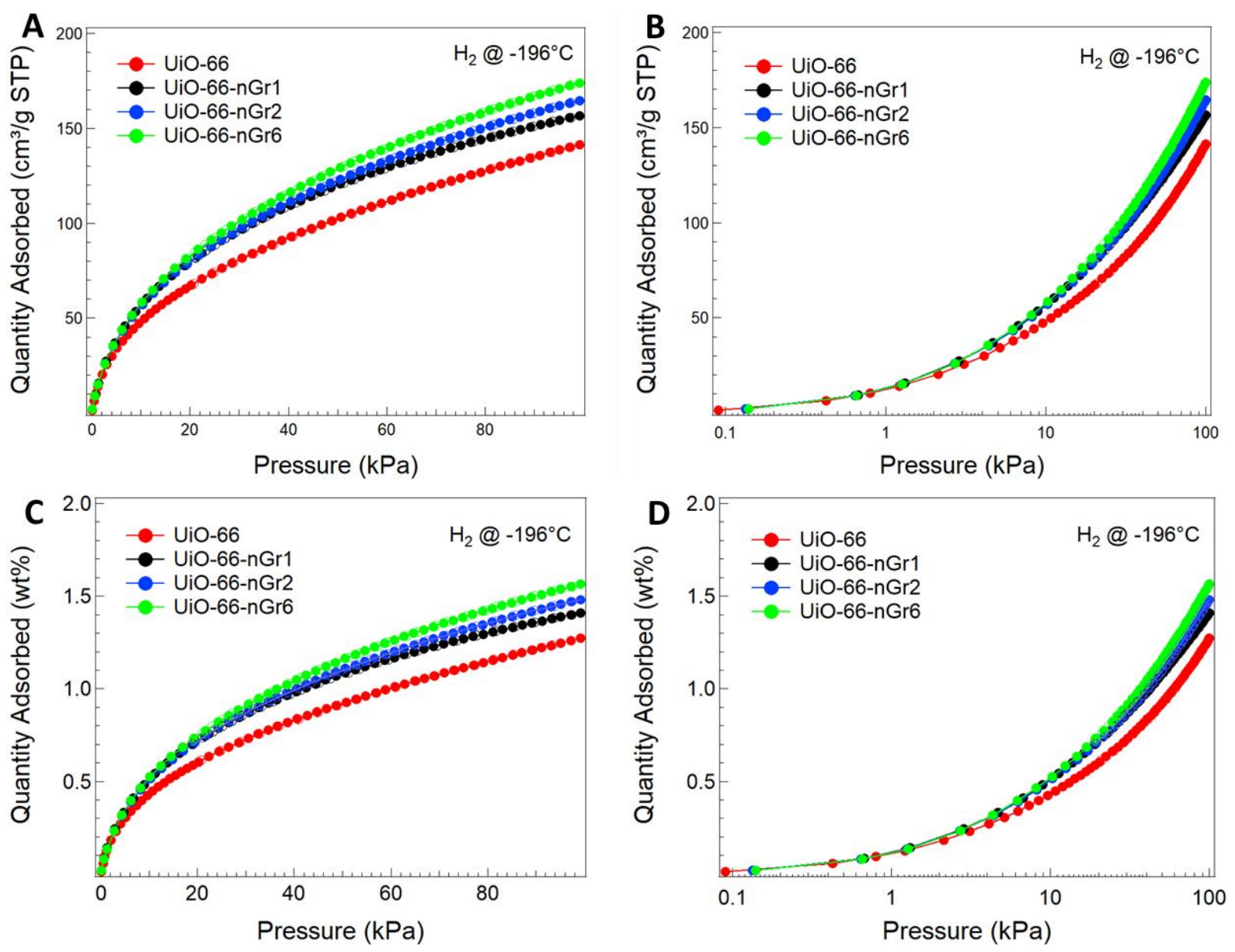

Figure 10. $\mathrm{H}_{2}$ adsorption isotherms on pure $\mathrm{UiO}-66$ and its composites at $-196^{\circ} \mathrm{C}$ in the pressure range 0-100 $\mathrm{kPa}$, reported in $\mathrm{cm}^{3} / \mathrm{g}$ and wt. \% on both $(\mathrm{A}, \mathrm{C})$ linear and $(\mathrm{B}, \mathrm{D})$ logarithmic scales. 

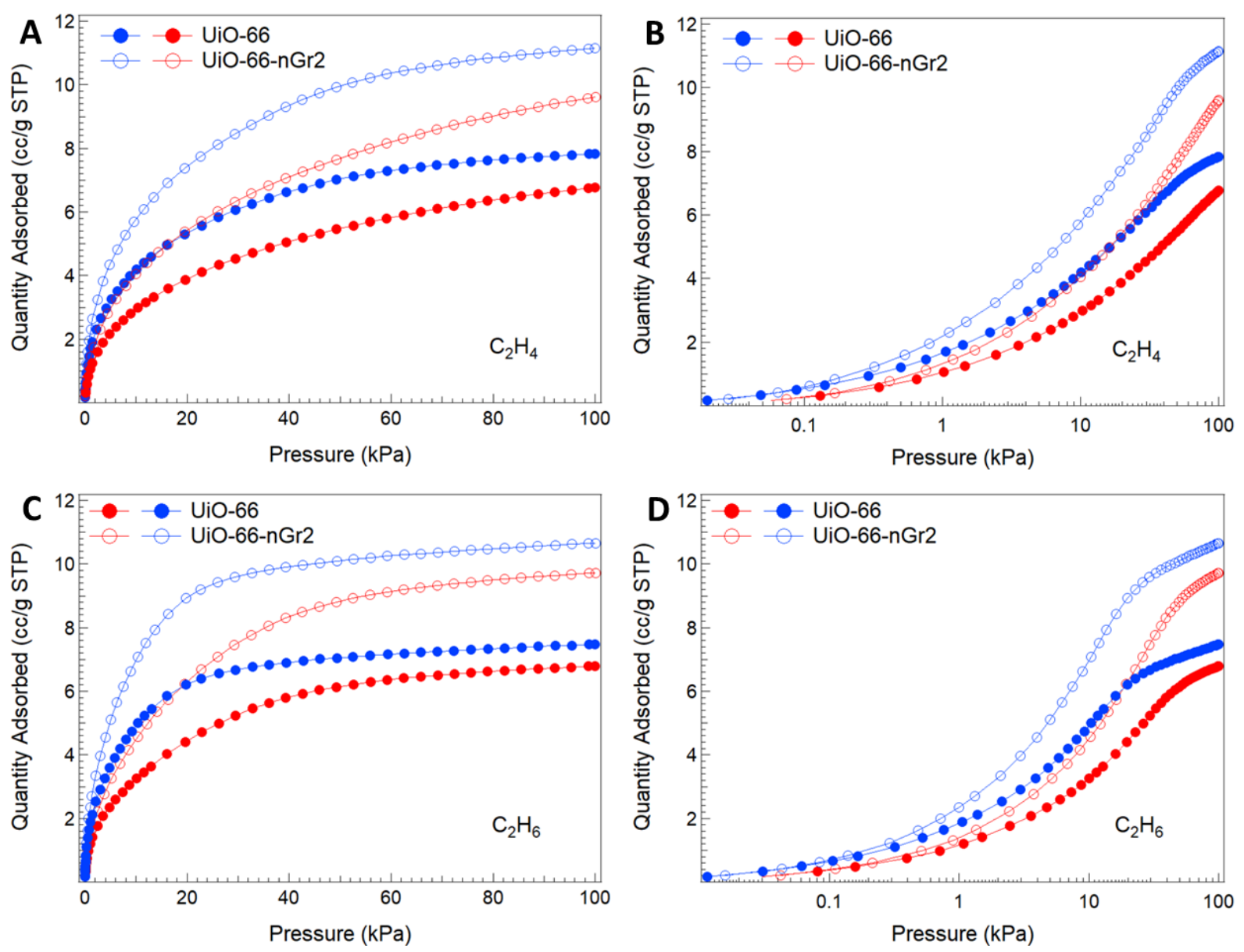

Figure 11. $\mathrm{C}_{2} \mathrm{H}_{4}$ adsorption isotherms in a linear (A) and logarithmic scale (B) and $\mathrm{C}_{2} \mathrm{H}_{6}$ adsorption isotherm in a linear (C) and logarithmic scale (D) on the UiO-66 composites at $-58^{\circ} \mathrm{C}$ (blue symbols) and $-73^{\circ} \mathrm{C}$ (red symbols) in the pressure range $0-100 \mathrm{kPa}$

To further explore the effects of composites texture and chemistry on the adsorption of small gas molecules, the adsorption of $\mathrm{C}_{2} \mathrm{H}_{4}$ and $\mathrm{C}_{2} \mathrm{H}_{6}$ was measured on UiO-66 and on UiO-66-nGr2 (Figure 11). Ethane and ethylene, besides having slightly different kinetic molecular sizes ( $\sigma$ for $\mathrm{C}_{2} \mathrm{H}_{4}$ and $\mathrm{C}_{2} \mathrm{H}_{6}$ is 0.416 and $0.444 \mathrm{~nm}$, respectively [42]), also differ in chemical properties with the former being more basic due to the presence of a $\pi$-bond [32]. Their adsorption was measured at -58 and $-73^{\circ} \mathrm{C}$ and the results are summarized in Table 2 . In this case, building the 
composite significantly increased the amounts of both $\mathrm{C}_{2} \mathrm{H}_{4}$ and $\mathrm{C}_{2} \mathrm{H}_{6}$ adsorbed compared to those on $\mathrm{UiO}-66$, and, on $\mathrm{UiO}-66-\mathrm{nGr} 2, \sim 42 \%$ more of both gases were adsorbed at $100 \mathrm{kPa}$. Since the differences in the overall porosity between these two samples are not so pronounced (the porosity of the composite is only about $25 \%$ higher), this difference might be caused by different extents of pore filling processes and in the accessibility of the pores. The affinity of hydrocarbons to adsorb on the graphite/graphite-UiO-66 interface might play a role. The biggest difference in the porosity between $\mathrm{UiO}-66$ and the composite is in pores with sizes $>0.7 \mathrm{~nm}$, and these pores seem to govern the amount of both gases adsorbed.

The comparison of the isosteric heats of $\mathrm{C}_{2} \mathrm{H}_{4}$ and $\mathrm{C}_{2} \mathrm{H}_{6}$ adsorption is presented in Figure $8 \mathrm{~B}$. $Q_{\text {st }}{ }^{o}$ for $\mathrm{C}_{2} \mathrm{H}_{4}$ is 26.1 and $24.7 \mathrm{~kJ} / \mathrm{mol}$ on $\mathrm{UiO}-66$ and on the composite, respectively. For $\mathrm{C}_{2} \mathrm{H}_{6}$, these values are 28.8 and $27.6 \mathrm{~kJ} / \mathrm{mol}$, respectively. The heats are consistent with those reported by Wang and co-workers [25]. The decrease in $Q_{\text {st }}{ }^{\mathrm{o}}$ with the coverage indicates that pores of various sizes are involved in the adsorption process, especially for ethane, those that are first occupied being the narrowest, for which the adsorption potential is the strongest. Therefore, the slightly higher heats at low surface coverage on UiO-66 might be due to the volume of pores with size $0.5-0.7 \mathrm{~nm}$ that is higher in pure $\mathrm{UiO}-66$ than in the composite. Then, with the progress of the adsorption process, the octahedral pores and these related to defects are filled and the composite has higher volume of such pore than has UiO-66.

The addition of nanographite had a positive effect on the gases adsorbed either by an increase in the narrow porosity or by an increase in the specific interactions with the nanographite phase, and could be a strategy to increase the gas adsorption capacity of MOFs. An exceptional hydrogen storage has indeed been achieved with SNU-70, UMCM-9, and PCN-610/NU-100, but analysis of trends revealed the existence of a volumetric ceiling at $\sim 40 \mathrm{~g} \mathrm{H}_{2} \mathrm{~L}^{-1}$ [43]. Surpassing 
this ceiling is proposed as a new capacity target for hydrogen adsorbents. In the same study, it was concluded that usable capacities in the highest-capacity materials are negatively correlated with density and volumetric surface area. Instead, the $\mathrm{H}_{2}$ capacity is maximized by increasing gravimetric surface area and the porosity, which have been enhanced by nanographite addition in the present study.

\section{Conclusions}

The adsorption of different small gas molecules allowed to clarify that the addition of even small amounts of nanographite phase, targeting 1,2 and 6 wt. \% in the composites during the synthesis of UiO-66, resulted in a marked $(\sim 30 \%)$ increase in the porosity. Ultramicropores narrower than $0.5 \mathrm{~nm}$ and pores wider than $0.7 \mathrm{~nm}$ were formed and they probably have their origin in defective UiO-66 deposited on the nanographite particles. These defects increased markedly the adsorbed amounts of $\mathrm{H}_{2}, \mathrm{CO}_{2}, \mathrm{C}_{2} \mathrm{H}_{4}$ and $\mathrm{C}_{2} \mathrm{H}_{6}$ on the composites compared to those on the parent UiO-66. Even though no direct dependence of the porosity on the amount of nanographite in the composites was found when the texture was analyzed by $\mathrm{N}_{2}$ adsorption, the increase in the quantity of hydrogen adsorbed with an increase in the nanographite content might indicate the existence of ultramicropores only accessible to $\mathrm{H}_{2}$. The isosteric heat of $\mathrm{CO}_{2}$ adsorption at zero surface coverage almost linearly increased with the nanographite content, suggesting the strong adsorption of $\mathrm{CO}_{2}$ on the interface. In the case of $\mathrm{H}_{2}$, its amount depended on the amount of nanographite suggesting the extensive effects of the interface or the improved diffusion of $\mathrm{H}_{2}$ to the smallest pores owing to the assembly of UiO-66 particle "walls" on the nanographite components. In the case of ethane and ethylene adsorption, besides an increased porosity of the composite, the interactions of these hydrocarbons with nanographite phase likely contributed to 
the marked increase in the amount adsorbed on the composite (42\%). The trends in the heats of adsorption (higher on pure UiO-66 than on the composite) suggested that these molecules adsorbed in tetrahedral, octahedral, and defects-related pores. In particular, the addition of nanographite appears as an especially interesting strategy to increase $\mathrm{H}_{2}$ adsorption capacity of MOFs. 


\section{References}

[1] S. Yuan, L. Feng, K. Wang, J. Pang, M. Bosch, C. Lollar, Y. Sun, J. Qin, X. Yang, P. Zhang, Q. Wang, L. Zou, Y. Zhang, L. Zhang, Y. Fang, Y. Li, H-C. Zhou, Stable metalorganic frameworks: design, synthesis and applications, Adv. Mater. 2018; 30: 170430.

[2] A.E. Baumann, D.A. Burns, B. Liu, V.S. Thoi, Metal-organic framework functionalization and design strategies for advanced electrochemical energy storage devices, Comms Chem.2019; 2; 86-99.

[3] Z. Fang, B. Bueken, D.E. De Vos, R.A. Fischer, Defect-Engineered Metal-Organic Frameworks, Angew. Chem. Int. Ed. 2015: 54, 7234-7254.

[4] G.C. Shearer, J.C. Vitillo, S. Bordiga, S. Svelle, U. Olsbye, K.P. Lillerund, Functionalizing the defects: postsynthetic ligand exchange in the metal organic framework UIO-66, Chem. mater. 2016; 28: 7190-7193.

[5] M. Taddei, R.J. Wakeham, A. Koutsianos, E. Andreoli, A.R. Barron, Post-synthetic ligand exchange in zirconium-based metal-organic frameworks: beware of the defects!, Angew. Chem. Int. Ed. 2018; 57: 11706-11710.

[6] B. Shan, S.M. McIntyre, M.R. Armstrong, Y. Shen, B. Mu, Investigation of Missing-Cluster Defects in UiO-66 and Ferrocene Deposition into Defect-Induced Cavities, Ind. Eng. Chem. Res. 2018; 57, 14233-14241.

[7] L. Yuan, M. Tian, J. Lan, X. Cao, X. Wang, Z. Chai, J.K. Gibbson, W. Shi, Defect engineering in metal-organic frameworks: a new strategy to develop applicable actinide sorbents, Chem. Comm. 2018; 54: 370-373. 
[8] L. Shen, R. Liang, M. Luo, F. Jing, L. Wu, Electronic effects of ligand substitution on metal-organic framework photocatalysts: the case study of UiO-66, Phys. Chem. Chem. Phys. 215;17:117-121.

[9] S. Dissegna, K. Epp, W.R. Heinz, G. Kieslich, R.A. Fischer, Defective metal- organic frameworks, Adv. Mater. 2018; 30: 1704501.

[10] J. M. Taylor, S. Dekura, R. Ikeda, H. Kitagawa, Chem. Mater. 2015, 27, 72286

[11] J.H. Cavka, S. Jakobsen, U. Olsbye, N. Guillou, C. Lamberti, S. Bordiga, K.P. Lillerud, A New Zirconium Inorganic Building Brick Forming Metal Organic Frameworks with Exceptional Stability, J. Am. Chem. Soc. 2008, 130, 13850-13851.

[12] M.J. Katz, Z.J. Brown, Y.J. Colon, P.W. Siu, K.A. Scheidt, R.Q. Snurr, J.P. Hupp, O.K. Farha, A facile synthesis of UiO-66, UiO-67 and their derivatives, Chem. Commun. 2013, 49, 9449-9451.

[13] M.R. De Stefano, T. Islamogle, S.J. Garibay, J.T. Hupp, O.K. Farha, Room-temperature synthesis of UiO-66 and thermal modulation of densities of defects, Chem. Mater. 2017:9: $1357-1361$

[14] T.G. Grissom, D.M. Driscoll, D. Troya, N.S. Sapienza, P.M. Usov, M.J. Morris, J.R. Morris, Molecular-level insight into $\mathrm{CO} 2$ adsorption on the Zirconium-based metal-organic framework, UiO-66: a combined spectroscopic and computational approach, J. Phys. Chem. C. $2019 ; 123: 13731-13738$.

[15]H.R. Abid, H. Tian, H-M. Ang, M.O. Tade, C.E. Buckley, S. Wang, Nanosize Zr-metal organic framework (UiO-66) for hydrogen and carbon dioxide storage, Chem. Eng. J. 2012; 187: 415-420. 
[16]H. Wu, Y.S. Chua, V. Krungleviciute, M. Tyagi, P. Chen, T. Yildirim, W. Zhou, Unusual and highly tunable missing-liker defects in zirconium metal-organic frameworks UiO-66 and their important effects on gas adsorption, J. Am. Chem. Soc. 2013; 135: 10525-10532.

[17] Y. Cao, Y. Zhao, Z. Lv, F. Song, Q. Zhong, Preparation and enhanced CO2 adsorption capacity of UiO-66/graphene oxide composites, J. Ind. Eng. Chem. 2015;27:102-107.

[18] A.R. Noorpoor, S. Nazri Kudahi, Analysis and study of CO2 adsorption on UiO66/graphene oxide composite using equilibrium modeling and ideal adsorption solution theory (IAST), J. Environ. Chem. Eng. 2016;4:1081-1091.

[19]H. Furukawa, F. Gandara, Y-B. Zhang, J. Jiang, W.L. Wueen, M.R. Hudson, O.M. Yaghi, Water adsorption in porous metal-organic frameworks and related materials, J. Am. Chem. Soc. $2014 ; 136:$ 4369-4382.

[20]P. Ghosh, Y.J. Colon, R.Q. Snurr, Water adsorption in UIO-66: the importance of defects, Chem. Comm. 2014; 50-11329-11331.

[21] Q. Zhao, W. Yuan, J. Liang, J. Li, Synthesis an hydrogen storage studies of metal organic framework UIO-66, Int. J. Hydrogen Energy. 2013; 38: 13104-13109.

[22]B.E.G. Lucier, Y. Zhang, K.J. Lee, Y. Lu, Y. Huang, Grasping hydrogen adsorption and dynamics in metal-organic frameworks using 2H solid-state NMR, Chem. Comm. 2016; 52: 7541-7544.

[23] J. Ren, H.W. Langmi, B.C. North, M. Mathe, D. Bessarabov, Modulated synthesis of zirconium-metalorganic framework (Zr-MOF) for hydrogen storage applications, Int. J. Hydrogen Energy. 2014; 39: 890-895.

[24] L. Zhang, L. Li, E. Hu, L. Yang, K. Shao, L. Yao, K. Jiang, Y. Cui, Y. Yang, B. Li, B. Chen, G. Qian, Boosting ethylene/ethane separation with copper(I)-chelated metal-organic 
frameworks through tailor-made aperture and specific p-complexation, Adv. Sci. 2020, $7: 1901918$.

[25]X. Wang, L. Li, Y. Wang, J-R. Li, J. Li, Exploiting the pore size and functionalization effects in UiO topology structures for the separation of light hydrocarbons, Cryst. Eng. Comm. 2017:19: 1729-1737.

[26] N. Chanut, A.D. Wiersum, U-H. Lee, Y.K. Hwang, F. Ragon, H. Chevreau, S. Bourrelly, B. Kuchta, J-S. Chang, C. Serre, P.L. Llewellyn, Observing the effects of shaping on gas adsorption in metal organic frameworks, Eur. J. Inorg. Chem. 2016; 27:4416-4423.

[27] N.A. Ramsahye, J. Gao, H. Jobic, P.L. Llewellyn, Q. Yang, A.D. Wiersum, M.M. Koza, V. Guillerm, C. Serre, C.L. Zhong, G. Mauron, Adsorption and diffusion of light hydrocarbons in UiO-66(Zr): a combination of experimental and modeling tools, J. Phys. Chem. C 2014; 118: $27470-27482$.

[28] A. Policicchio, M. Florent, M.F. Attia, D.C. Whitehead, J. Jagiello, T.J. Bandosz, Effect of the incorporation of functionalized cellulose nanocrystals into UiO-66 on composite porosity and surface heterogeneity alterations, Adv. Mater. Interfaces. 2020, 1902098.

[29]D.A. Giannakoudakis, T.J. Bandosz, Defectous UiO-66 MOF Nanocomposites as Reactive Media of Superior Protection against Toxic Vapors, Chem. Eng. J. 2020, 3984, 123280

[30] M. Thommes, K. Kaneko, A.V. Neimark, J.P. Olivier, F. Rodriguez-Reinoso, J. Rouquerol, K.S.W. Sing, Pure Appl. Chem. 2015; 87: 1051-1069.

[31] M. Seredych, J. Jagiello, T.J. Bandosz, Complexity of CO2 adsorption on nanoporous sulfur-doped carbons: Is surface chemistry an important factor?, Carbon 2014; 74: 207-2017 
[32] T.J. Bandosz, K. Putyera, J. Jagiello, J.A. Schwarz, Application of inverse gas chromatography to the study of the surface properties of modified layered minerals, Micro. Mater. 1993; 1: 73-79.

[33] J. Jagiello, J.P. Olivier, Carbon slit pore model incorporating surface energetical heterogeneity and geometrical corrugation, Adsorption 2013; 19:777-783.

[34]L. Czepirski, J. Jagiello, Virial-type thermal equation of gas—solid adsorption, Chem. Eng. Sci. 1989; 44: 797-801

[35] R. Heck, O. Shekhah, O. Zybaylo, P.G. Weidler, F. Friedrich, R. Maul, W. Wenzel, C. Woll, Loading of two related metal-organic frameworks (MOFs), [Cu2(bdc)2(dabco)] and (Cu2(ndc)2(dabco)], with ferrocene, Polymers 2011; 3L 1565-1574.

[36] Y. Han, M. Liu, K. Li, Y. Zuo, Y. Wei, S. Xu, G. Zhang, C. Song, Z. Zhang, X. Guo, Facile synthesis of morphology and size-controlled zirconium metal-organic framework UiO-66: the role of hydrofluoric acid in crystallization, Cryst. Eng. Comm. 2015; 17: 6434-6440.

[37] C.A. Clark, K.N. Heck, C.D. Powell, M.S. Wong, Highly Defective UiO-66 Materials for the Adsorptive Removal of Perfluorooctanesulfonate, ACS Sustainable Chem. Eng. 2019: 7: 6619-6628.

[38] D.H. Everett, J.C. Powl, Adsorption in slit-like and cylindrical micropores in the Henry's law region, J. Chem. Soc. Faraday Trans. 1984; 619-621.

[39] J. Jagiello, J. Kenvin, A. Celzard, V. Fierro, Enhanced resolution of ultra micropore size determination of biochars and activated carbons by dual gas analysis using $\mathrm{N} 2$ and $\mathrm{CO} 2$ with 2D-NLDFT adsorption models, Carbon 2019; 144: 206-215.

[40] J. Jagiello, J. Kenvin, C.O. Ania, J.B. Parra, A. Celzard, V. Fierro, Exploiting the adsorption of simple gases $\mathrm{O} 2$ and $\mathrm{H} 2$ with minimal quadrupole moments for the dual gas 
characterization of nanoporous carbons using 2D-NLDFT models, Carbon 2020; 160: 164175.

[41] A.D. Buckingham, R.L. Disch, D.A. Dunmur, Quadrupole moments of some simple molecules, J. Am. Chem. Soc. 1968; 90: 3104-3107.

[42] S. Aguado, G. Bergeret, C. Daniel, D. Farrusseng, Absolute molecular sieve separation of ethylene/ethane mixtures with silver zeolite A, J. Am. Chem. Soc. 2012, 134, 14635-14637

[43] A. Ahmed, S. Seth, J. Purewal, A.G. Wong-Foy, M. Veenstra, A.J. Matzger, D.J. Siegel, Exceptional hydrogen storage achieved by screening nearly half a million metal-organic frameworks, Nat. Commun. 2019; 10: 1-9. 